\title{
REFLEXÕES SOBRE FORMAÇÃO DA IDENTIDADE PROFISSIONAL DO PROFESSOR DE SOCIOLOGIA NA EDUCAÇÃO BÁSICA
}

\author{
REFLECTIONS ABOUT OF THE FORMATION OF SOCIOLOGY TEACHER'S PROFESSIONAL \\ IDENTITY IN SECONDARY EDUCATION
}

Josefa Alexandrina SILVA1

\begin{abstract}
Resumo: A introdução do ensino da Sociologia na educação básica colocou em questão a necessidade de compreender quem são seus professores, suas concepções de ciência, formação e trajetórias de trabalho. Analisou-se a constituição de um quadro docente e suas dificuldades de profissionalização a partir de três questôes: as relaçôes do professor com as Ciências Sociais; as distorçôes entre formação e atuação e as condições de trabalho. Tomou-se como referência as reflexôes de Nóvoa (1992) sobre a centralidade do professor no sistema educacional e a contribuiçóes de Dubar (2005) sobre a formação das identidades profissionais. Parte-se da produção acadêmica sobre o tema, para analisar as dificuldades de constituição de um quadro docente com identidade profissional definida. As análises indicam que a grande incidência de professores sem formação específica e as condiçóes estruturais em que é oferecido o ensino, constituem entraves no processo de consolidação do ensino da Sociologia na educação básica.
\end{abstract}

Palavras chaves: Ensino de Sociologia. Professor. Identidade Profissional. Formação. Condições de Trabalho.

\begin{abstract}
The introduction of Sociology teaching at the Secondary level has put into question the necessity of understanding who are its teachers, their conceptions of Science, their formation, and their work trajectories. The constitution of a teaching staff has been analysed, as well as the difficulties of its professionalization through three main questions: the relations between the teacher and the Social Science; the distortions between formation and performance; and the working conditions. Nóvoa's (1992) reflections about the centrality of the teacher in the educational system and Dubar's (2005) contributions about the formation of professional identities have been taken as reference. This research is built on the scholar production about the theme to analyse the difficulties of the constitution of a teaching staff with definite professional identity. The analyses indicate that the great incidence of teachers without specific formation and the structural conditions in which the teaching is offered constitute hindrances in the process of consolidation of Sociology teaching at the Secondary level.
\end{abstract}

Keywords: Sociology Teaching. Teacher. Professional Identity. Formation. Working conditions.

1. É doutoranda do Programa de Pós-Graduação da Faculdade de Educação da Universidade de São Paulo. Possui bacharelado e licenciatura em Ciências Sociais pela Pontifícia Universidade Católica de São Paulo e mestrado em Ciências Sociais pela mesma instituição. É professora adjunta da Universidade Paulista. E-mail: j.alexandrina@uol.com.br 


\section{INTRODUÇÃO}

Sob a perspectiva das teorias contemporâneas do currículo, a reforma instituída pela Lei n. ${ }^{\circ} 11.684$ de 2007 , que tornou obrigatório o ensino de sociologia no ensino médio, significou a introdução das Ciências Sociais no campo da disputa pelas significaçóes do currículo.

Se o currículo é o espaço simbólico de embates, como nos afirma Tomás Tadeu da Silva (1999), a disputa curricular implica na existência de sujeitos capazes de discernir os interesses e argumentar em torno da defesa dos significados. No campo das Ciências Sociais, isso significa que o professor necessita ter uma formação consistente na área, que contribua para que os estudantes superem o senso comum e compreendam a realidade social.

Este texto privilegia a análise do professor, pois é esse ator que faz a intermediação entre as políticas curriculares e os estudantes no interior das escolas. Por isso concentra esforços para compreender quem são esses atores e suas visóes sobre o ensino.

A implementação da Lei 11.684 de Junho de 2007 ocorreu em um cenário onde a maioria dos professores que ministra aulas de Sociologia não possui formação na área. Diante desse contexto, analisam-se as formaçóes identitárias dos professores e questionam-se as possibilidades de intervenção no debate atual sobre a obrigatoriedade do ensino da Sociologia. ${ }^{2}$

Parte-se da revisão das pesquisas que tem o professor de Sociologia como objeto de investigação para compreender a constituição da identidade docente a partir de sua formação e das interaçóes sociais estabelecidas nas escolas.

Os campos escolar e profissional são vistos como áreas primordiais de identificaçôes sociais dos indivíduos. $\mathrm{Na}$ análise dos vínculos entre emprego-formação, Dubar (2005) considera que, a partir dos anos de 1980, a formação se tornou um componente cada vez mais valorizado para o acesso e permanência nos empregos. Assim, justifica-se a estreita relação entre formação, emprego e processos identitários.

Em estudo realizado sobre a formação da identidade profissional dos professores em Portugal, até o final do século XIX, Nóvoa (1995) revela que a atividade docente esteva ligada a uma visão do magistério como vocação e sacerdócio. A expansão da educação pública sob o controle estatal no século XX foi vista pelo autor como desencadeadora da formaçáo de uma nova identidade que concebe o magistério como profissão.

Nas últimas décadas, o conceito de centralidade do professor ganha relevância nos estudos na área de educação. Mas, em diversos países, as propostas políticas são carregadas de ambiguidades: defende-se a valorização da carreira e cria-se sistemas apostilados que tendem a secundarizá-los, como pontua Nóvoa, a seguir:

2. Referimo-nos aqui à Medida Provisória 746 que institui a Reforma no Ensino Médio e coloca sob suspeição a continuidade do ensino de Sociologia na educação básica. 
Por um lado, os professores são olhados com desconfiança, acusados de serem profissionais medíocres e de terem uma formação deficiente; por outro lado, são bombardeados com uma retórica cada vez mais abundante que os considera elementos essenciais para a melhoria da qualidade do ensino e para o progresso social e cultural (NÓVOA, 1999, p. 2-8).

Isso traz para o centro da reflexão compreender como os professores constituem sua identidade como profissionais. No campo das pesquisas educacionais, esses estudos se desenvolveram a partir das reformas educacionais dos anos de 1980 na Europa. A intensificação do trabalho docente, o aumento das funçôes burocráticas e a criação de sistemas de controle e avaliação de desempenho compóem o cenário de atuação dos professores e colocaram sob questão o sentido da profissão (ZANTEN, 2011).

O trabalho com a docência possui uma dimensão intelectual de envolvimento com uma área do conhecimento e uma dimensão social de convívio com as demandas da comunidade escolar. Para Goodson (2008), o profissionalismo docente é algo maior que o emprego, pois se trata de um trabalho carregado de objetivo e significado. Mas a retirada da "[...] ênfase no processo de construção do conhecimento local, diminui o papel do docente, enquanto decisor e agente de mudança” (GOODSON, 2008, p. 96).

A partir da análise de estudos que trata o professor de Sociologia como objeto de investigação, procurou-se identificar as configuraçôes de identidade possíveis. Analisaram-se as relaçôes do professor com as Ciências Sociais, as distorçôes entre formação e atuação e suas interações sociais no campo escolar.

Como já foi abordado em outros trabalhos (MACHADO, 1987; MORAES, 2003), a falta de continuidade nas políticas curriculares no passado conduziu o ensino de Sociologia na educaçáo básica a não consolidar uma tradição de ensino.

A trajetória intermitente da disciplina conduziu os licenciados na área a ministrarem outras disciplinas como História e Geografia e a ocuparem posições de trabalho precário como temporários e eventuais. Para Lennert (2011) isso conduziu os professores de Sociologia a uma situação de maior vulnerabilidade se comparados aos professores de outras disciplinas.

Desde que o ensino de Sociologia se tornou obrigatório em todas as séries do ensino médio, colocou-se a possibilidade de atuar na sua área de formação. Mas sua inserção no campo escolar requer análise de como relacionam a ciência com a disciplina escolar, das suas formas de socialização na escola e como constituem sua identidade profissional.

Apesar de se considerar os professores de Sociologia como grupo profissional específico em razão da sua história, de suas características de formação, postula-se que devem ser compreendidos 
no contexto das reformas educacionais que tem abalado o sentido do trabalho do professor.

As análises dos estudos que tem o professor de Sociologia na educação básica como objeto, realizadas em diferentes Estados, indicam que a grande incidência de professores sem formação específica e as relações sociais de trabalho na educação básica constituem entraves para a consolidação do ensino na educação básica.

\section{FORMIAÇÃO CIENTÍFICA E IDENTIDADE PROFISSIONAL}

Quando se interroga sobre a formação da identidade profissional do professor de Sociologia, deve-se considerar como as singularidades da disciplina impactam o seu o trabalho. Como ciência, a Sociologia é vista como uma área de conhecimento que necessita constantemente comprovar seu estatuto científico.

Por ter como objeto de estudo as relaçóes sociais, as proposiçóes na Sociologia tendem a incomodar os interesses de grupos sociais. $\mathrm{Na}$ medida em que o conhecimento sociológico atua no sentido de "desmistificar a realidade social", torna-se uma ciência que incomoda. Por isso é acusada de ser política, de ser movida por interesses e paixóes, pois "[...] toda proposição que contradiz as ideias estabelecidas, está exposta a suspeita de preconceito ideológico, de tomada de posição política” (BORDIEU, 1980, p. 01).

A Sociologia opera com sistemas de hipóteses, conceitos e métodos de análise como as outras ciências. Mas pela natureza do seu objeto de pesquisa, necessita constantemente reivindicar o seu estatuto científico. Isso conduz a Sociologia a ter de apresentar sempre as provas dos dados coletados.

A Sociologia possui limites imprecisos de separação do senso comum, colocando a necessidade constante de submeter à reflexão a análise epistemológica. Seus temas de ensino possuem interpretaçóes no senso comum, por estarem presentes no cotidiano dos estudantes. Nesse sentido, Bourdieu (1994) problematiza a prática educacional que tende a subordinar a reflexão rigorosa à didática, para tornar o conhecimento acessível aos estudantes. Para o professor, coloca-se a necessidade de realizar uma luta simbólica contra as interpretaçôes simplistas do senso comum e demonstrar a análise científica desses temas.

A partir das consideraçóes de Bourdieu sobre os aspectos da Sociologia que a tornam uma ciência que incomoda, conclui-se que esses aspectos reverberam no campo do ensino escolar e colocam o professor diante de uma ação mais reflexiva e intelectualizada que é conflitante com o modelo de organização escolar voltada para um conhecimento pragmático.

Em estudo realizado com professores que possuem formação em Ciências Sociais, Santos (2002) identificou a centralidade da formação universitária na constituição de suas identidades. Esses docentes se vêm como "[...] sujeitos se identificando como portadores de um conhecimento 
especializado. É como especialistas, eles se percebendo em um patamar de entendimento da realidade social diferenciado." (SANTOS, 2002, p. 103).

Como portadores de um conhecimento especializado que os professores pesquisados por Santos (2002) concebem que o seu trabalho na educação básica. Nesse sentido, identificam que o objetivo de seu trabalho é contribuir para que os estudantes compreendam a realidade social a partir da formação de uma consciência sociológica.

Para esse autor, a concepção de ciência e as ideias compartilhadas sobre o ofício possibilitam a formação de laços sociais entre os professores, o que pode promover a mobilização desses atores para execução de objetivos comuns, como a busca da legitimidade da disciplina na educaçáo básica, como se vê a seguir:

[...] parece que a busca da afirmação da sociologia como instrumento de conscientização, também seria a busca da afirmação da identidade do professor dessa disciplina. Cabe salientar ser esse discurso, embora não exclusivo, típico de um professor com formação em Ciências Sociais. Um profissional que talvez em função dessa formação, se percebe detentor de um conhecimento especializado. Um saber científico que lhe propiciaria uma consciência mais ampla, sofisticada e sistematizada acerca da realidade social (SANTOS, 2002 p. 105).

A formação da identidade profissional na perspectiva de análise de Santos (2002) é voltada para si. Em outras palavras, é a partir da sua relação com o conhecimento que o sujeito constrói a sua identidade como profissional.

Como se pôde ver, a formação acadêmica é elemento primordial na formação da identidade dos professores. Essa estreita relação entre formação, trabalho e processos identitários conduz a considerar que o menosprezo com a formação científica na área acarreta a própria banalização da identidade profissional.

\section{A DISTORÇÃO ENTRE FORIMAÇÃO E ATUAÇÃO}

O Censo Educacional da Educação Básica é realizado anualmente pelo INEP com dados coletados em todas as escolas do país. São aplicados questionários individuais para os docentes com questôes sobre formação e condiçôes de trabalho. Atualmente se constituiu em um instrumento importante para se vislumbrar o panorama do ensino de Sociologia na educação básica no país.

Estudo realizado pelo INEP, com base nos dados do senso educacional de 2013, indica que para atender a demanda nacional o país necessita atualmente de 16,8 mil professores exclusivos de Sociologia, com jornada de $40 \mathrm{~h}$, sendo um terço da jornada dedicada a estudos e projetos. 
O mesmo estudo do INEP indica que no Brasil, entre 2001 e 2013, concluíram os cursos de Licenciatura em Ciências Sociais/Antropologia 29,9 mil estudantes. Tecnicamente, esse número seria suficiente para atender a demanda nacional de professores. Porém, o estudo não analisa a distribuição desses profissionais pelo território, seu objetivo é dar uma visão panorâmica do perfil dos docentes no país. Isso coloca a necessidade de realizar estudos que analisem as particularidades regionais do país.

Segundo o estudo do INEP, dos docentes que se dedicam ao ensino de Sociologia na educação básica, apenas 11,8\% possuem formação específica na área. Os dados indicam que os professores que não possuem formação em Ciências Sociais têm formação na área de Ciências Humanas, em cursos de História, Filosofia, Pedagogia, Letras, entre outros.

A distorção entre formação e atuação é um fenômeno da educação no país, presente em todas as áreas do conhecimento. A falta de identificação dos docentes com as especificidades da área de conhecimento se transforma em obstáculo para que o envolvimento no debate curricular e fragiliza a disciplina no contexto escolar.

No campo das Ciências Sociais, como os seus temas se aproximam do cotidiano, o senso comum tende a considerar que seus conteúdos podem ser ministrados por profissionais de outras áreas, o que banaliza o conhecimento da disciplina e faz que seu ensino da educação básica seja inócuo. ${ }^{3}$

As distorções entre formação e atuação conduzem a diferentes percepções sobre o sentido da disciplina na educação básica. A pesquisa de Santos (2002), com professores do Distrito Federal, indicou que os professores que não possuem formação específica tendem a considerar que o papel da disciplina é formar a consciência política e direcionar os estudantes para algum tipo de intervenção social. Desse modo, propagam uma visão da Sociologia como uma ideologia.

Para compreender como o sistema educacional possibilita distorçôes que comprometem o sentido do aprendizado, recorremos ao estudo de Ileizi Silva (2004) sobre a implantação do ensino de Sociologia na região de Londrina. A pesquisadora identifica que a origem desse problema se encontra na burocracia educacional, como se observa a seguir:

É interessante observar mais um problema estrutural da burocracia educacional, que
não consegue racionalizar o potencial dos professores de acordo com suas habilitaçôes
e formaçóes. Além disso, demonstra que a administração não está preocupada com a
qualidade das aulas e do ensino, porque admite que professores trabalhem 40 horas ou
mais em sala de aula em mais de uma disciplina. No caso das Ciências Humanas isso
tem sido trágico para a qualidade das aulas (SILVA, Ileizi, 2004 p. 87).

3. De modo similar, pesquisa realizada por Ileizi Silva em 1999, momento de introdução do ensino de Sociologia nas escolas de Londrina, relatou que as aulas eram assumidas por pedagogos, advogados, contabilistas e outros profissionais que haviam perdido suas aulas em virtude do fim da obrigatoriedade do ensino profissionalizante. 
Embora a distorção entre formação e atuação não seja um fenômeno específico da área de Ciências Sociais, para o conhecimento escolar torna-se preocupante, pois o conhecimento é banalizado e pode se confundir com senso comum e ideologias.

$\mathrm{Na}$ constituição da identidade docente, as relaçôes sociais estabelecidas indicam que se atribui uma identidade genérica ao professor, que pode ocupar um lugar indeterminado no sistema escolar.

\section{RELAÇÕES SOCIAIS E DE TRABALHO}

Procurou-se demonstrar até aqui a importância da formação na constituição da identidade profissional. Analisou-se como as experiências individuais ligadas à formação refletem na visão do professor sobre o seu trabalho e como as distorçôes entre formação e atuação conduzem a uma identidade genérica.

Recorremos agora à análise de Dubar (2004) sobre indistinção entre identidade individual e a coletiva. A identidade é constituída nos processos de socialização que engloba aspectos objetivos e subjetivos, além de elementos biográficos e de análise da estrutura social.

A construção da identidade profissional é um processo complexo e inacabado que se forma a partir de vivências em inúmeros espaços, como a família, a classe social, etnia, gênero. Ela é fruto das formas como os indivíduos internalizam suas vivências, e está ligada à forma como o indivíduo constrói a sua maneira de ser profissional.

Para essa análise, pensar a formação da identidade profissional do professor de Sociologia a partir dos processos de socialização significa analisar a maneira como esses processos se inserem no ambiente escolar.

A partir de uma abordagem que considera a construção da identidade a partir das interações sociais, encontramos na pesquisa de Sousa (2012) relatos que indicam dificuldades de formação de uma identidade profissional entre professores de Picos no Piauí. A pesquisa deu voz aos professores, que relatam suas percepçóes sobre o ensino na cidade. Dos professores investigados, a maioria não possui formação específica em Ciências Sociais.

Sua pesquisa não toma como referência a formação, mas a construção da identidade nos espaços educacionais, na interação com docentes de outras disciplinas, alunos, coordenadores e diretores. Com uma análise centrada mais nas situaçôes cotidianas, a pesquisadora relata casos de discriminação e desvalorização dos professores de Sociologia. Relata que os entrevistados se veem desestimulados e sozinhos dentro da disciplina.

Muitos se tornaram professores de Sociologia em virtude das carências da escola e para complementar carga horária. Afirmam que o contato com a Sociologia os fez crescer como pessoa e 
reconhecem que o sentido de ser professor de Sociologia é ser "agente da transformaçáo social" e se sentem comprometidos com as causas sociais. Indicam ainda que a falta de experiência acumulada na didática do ensino de sociologia constitui uma dificuldade adicional ao ensino da disciplina.

Os professores entrevistados por Sousa (2012) relatam resistência e falta de acolhimento por parte dos alunos, gestores e professores de outras áreas. Como a autora afirma a seguir:

Na composição dos horários de aulas, as aulas de Sociologia são colocadas nos últimos horários, sob a alegação de que é melhor os alunos faltarem nas aulas de Sociologia do que de Português ou Matemática, desconsiderando-se a importância da disciplina na formação dos alunos (SOUSA, 2012, p. 40).

Como se vê nos relatos, a implantação da sociologia como disciplina encontra resistências que se expressam nas relaçóes que se estabelece com os professores, conduzindo a situaçôes de isolamento. Desse modo, estima-se que as dificuldades de socializaçáo dos professores podem comprometer o seu engajamento nas atividades da escola e consequentemente da comunidade em que estão inseridos.

Martins e Sobral (2015) pesquisaram os licenciados em Ciências Sociais que atuam na cidade de Goiânia entre 2009 e 2010 . As pesquisadoras partem de uma perspectiva de análise que privilegia os aspectos estruturais do trabalho docente e suas relaçôes com as transformaçôes contemporâneas no mundo do trabalho. Em um cenário de privatização crescente da educação pública no estado de Goiás, onde tem prevalecido açóes de burocratizaçáo do ensino com a uniformização de conteúdos, metas e projetos, intensificou-se o trabalho docente. Nesse cenário, as pesquisadoras constataram que as condiçôes de trabalho têm conduzidos os professores a doenças e desmotivação.

Como a carga horária reduzida, os professores formados em Ciências Sociais são obrigados a assumir outras disciplinas na área de Ciências Humanas, o que dificulta o estudo, preparo de aulas e projetos para a disciplina para que são habilitados. Assim, coloca-se em risco as possibilidades de desenvolver os conteúdos de forma problematizada e contextualizada.

Para as autoras, a precarização das condiçôes de trabalho dos professores de Sociologia, quando comparadas aos professores de outras áreas do conhecimento, é ainda maior, porque os professores de Sociologia:

Permanecem pouco tempo nas escolas, pelo fato de lecionarem apenas uma aula por semana em cada uma das turmas do ensino médio. Estes professores enfrentam maior dificuldade em estabelecer vínculos com os demais profissionais e com os alunos, já que sua presença no ambiente educacional é 'esporádica'; além do que tem pouco, ou nenhuma voz, nas decisóes coletivas, visto que sua presença na escola nem sempre ocorre nos momentos de reuniôes (MARTINS; SOBRAL, 2015 p. 09). 
Constata-se que as formas de organizaçáo do trabalho docente, marcadas por uma pequena carga horária para a disciplina e a falta de compreensão do seu significado no currículo por parte de professores de outras disciplinas, direçôes e coordenaçôes, dificultam a interação dos professores de Sociologia com a dinâmica da vida escolar. Criam-se barreiras que dificultam sua atuação como ator central do processo de ensino. Essas condiçôes afetam os professores de todas as áreas, mas a chegada tardia da Sociologia no currículo torna seus docentes ainda mais vulneráveis.

Como nos alerta Bourdieu (1994), o processo de ensino requer do professor uma prática fundamentada em conhecimentos sociológicos, o que exige reflexão e trabalho intelectual que se demonstram incompatíveis com o modelo de organização vigente nas escolas.

Para a formação da identidade do professor, coloca-se a dificuldade de conceber-se enquanto trabalhador de atividade intelectual. As condiçóes de trabalho dificultam o desenvolvimento de atividades de natureza científica, como leituras, discussóes e produção textual, "[...] instala a dificuldade de o professor definir-se enquanto trabalhador de atividade intelectual ou técnica" (ERAS, 2007 p. 8). Não é por acaso que há uma extrema valorização do livro didático e dos sistemas apostilados, que tendem a cristalizar o conhecimento e secundarizar o trabalho do professor.

O conhecimento que o professor de Sociologia na educação básica possui, advindo de diferentes localidades do país, indica que o processo de consolidação de seu ensino encontra obstáculos nos aspectos estruturais da docência, como formação, carga horária e a condição da escola pública. Nesse sentido, sua consolidação se encontra vinculada a mudanças mais amplas na educação.

A condição considerada ideal para o exercício da docência, segundo o MEC, seria que os professores tivessem formação específica na área em que atuam. Os professores teriam que atuar em uma única escola e ter $2 / 3$ da jornada de trabalho em sala de aula. Enquanto a condição ideal não se transforma em real, temos um cenário que indica que os objetivos da inserção do ensino da Sociologia na educação básica ainda se encontram distantes de serem alcançados.

\section{CONSIDERAÇÕES FINAIS}

Procurou-se compreender as configuraçôes de identidade do professor de Sociologia a partir da chegada tardia da disciplina no campo da disputa curricular. A natureza do conhecimento científico que dá referência à disciplina escolar insere o professor no campo da disputa por significaçóes do currículo.

Em virtude de uma trajetória de idas e vindas no currículo, a Sociologia como disciplina escolar não possui ainda reconhecimento social, que muitas vezes é confundido com discursos ideológicos ou com a reproduçáo do senso comum. Isso coloca para o professor a necessidade de enfatizar constantemente o caráter científico dos conhecimentos na área. A valorização do saber teórico é considerada um valor fundamental na constituição da identidade do professor. 
A grande incidência de professores sem formação específica, além de conduzir à banalização do conhecimento, conduz à formação de uma identidade genérica de um docente sem um lugar definido no sistema educacional.

As condiçôes de trabalho são vistas por Dubar (2005) como primordiais na constituição das identidades. Como podemos ver, a carga horária reduzida e a necessidade de atuar em várias escolas dificultam a criação de laços com a instituição escolar e conduzem os professores a um lugar secundário.

Os estudos sobre as configurações identitárias do professor de Sociologia devem ser aprofundados com mais pesquisas qualitativas que procurem compreender o sentido que os professores atribuem ao seu trabalho.

\section{REFERÊNCIAS}

BOURDIEU, Pierre. Uma ciência que perturba. Entrevista a Pierre Thuiller. In: Questóes de sociologia. Rio de Janeiro: Marco Zero, 1980 p. 1-15.

BOURDIEU, P.; CHAMBOREDON, Jean-Claude et PASSERON, Jean-Claude. El oficio de sociólogo. 17a. edicion. Madrid: Siglo Veintiuo Editores, 1994.

BRASIL. Ministério da Educação. Orientaçóes Curriculares para o Ensino Médio: Ciências Humanas e suas tecnologias. Secretaria de Educação Básica, 2006.

CENSO ESCOLAR 2013 : Perfil da Docência no ensino médio regular - Brasília,DF :Instituto Nacional de Estudos e Pesquisas Educacionais Anísio Teixeira, 2015.110 p. Disponível em: <http://www.publicacoes.inep.gov.br/portal/download/1281>. Acesso em: 12 nov. 2015.

DUBAR, Claude. A socialização: construção das identidades sociais e profissionais. São Paulo: Martins Fontes, 2005.

ERAS, Lígia; CAMARGO, Wander. O trabalho docente em Sociologia e Filosofia no ensino médio: entre angústias e expectativas. In: CONGRESSO BRASILEIRO DE SOCIOLOGIA. UFPE, 13., 2007, Recife. Disponível em: <http://www.labes.fe.ufrj.br/?cat_id=7\&sec_id=17>. Acesso em: 20 jan. 2016.

GOODSON, Ivor. Conhecimento e Vida Profissional. Porto: Porto Editora, 2008.

LENNERT, Ana Lúcia. Condiçôes de trabalho do professor de Sociologia. Cad. CEDES, Campinas, v.31, n.85, p.383-403, dez.2011. Disponível em: <http://www.scielo.br/scielo.php?script=sci_arttext\&pid=S0101-32622011000300005\&lng=pt\&nrm=iso >. Acesso em: 20 out. 2015.

http://dx.doi.org/10.1590/S0101-32622011000300005. 
MACHADO, Celso de Souza. O ensino da Sociologia na escola secundária brasileira: Levantamento preliminar. Revista da Fac. Educ., São Paulo. v.13, n.1, p. 115-142, jan./jun. 1987. Disponível em: <http:// educa.fcc.org.br/pdf/rfe/v13n1/v13n1a05.pdf>. Acesso em: 18 out. 2015.

MORAES, Amaury Cesar. Licenciatura em ciências sociais e ensino de sociologia: entre o balanço e o relato. Tempo soc., São Paulo, v. 15, n. 1, p. 5-20, abr. 2003. Disponível em: <http://www.scielo.br/scielo. php?script=sci_arttext\&pid=S0103-20702003000100001\&lng=pt\&nrm=iso $>$. Acesso em: 06 out. 2015. http://dx.doi.org/10.1590/S0103-20702003000100001.

NÓVOA, Antônio. Formação de Professores e Profissão Docente. IN: NÓVOA, A. (coord.) Os professores e a sua formaçáo. Lisboa: Dom Quixote, 1992 p. 13-33

Os professores na virada do milênio: do excesso dos discursos à pobreza das práticas. Educ. Pesq., São Paulo, v.25, n. 01, Jun 1999.

SILVA, Ileizi L.F. A Sociologia no ensino médio: perfil dos professores, dos conteúdos e das metodologias no primeiro ano de reimplantaçáo nas escolas de Londrina - PR e região - 1999. In: CARVALHO, Lejeune M.G. Sociologia e Ensino em Debate: Experiências e discussão de Sociologia no ensino médio. Ijui: Ed. Unijuí, 2004.

SILVA, Tomás Tadeu. O currículo como prática de significação. In: $\mathbf{O}$ currículo como fetiche: a poética e a política do texto curricular. Belo Horizonte: Autêntica, 1999.

SOUSA, Maria das Dôres. Identidade e Docência: o saber fazer do professor nas escolas públicas estaduais de Picos - PI. Natal: RN, 2012. Tese (Doutorado em Educaçáo) Universidade Federal do Rio Grande do Norte. Disponível em: <http://www.labes.fe.ufrj.br/?cat_id=7\&sec_id=18>. Acesso em: 12 out .2015.

ZANTEN, Agnès van. Dicionário de Educação. Petrópolis, RJ: Vozes, 2011. 